\title{
P. N. TKACHEV, EL PREDECESOR DE LENIN CON (SIN) IMPACTO \\ Ondrej Marchevsky*
}

RESUMEN: El artículo se centra en el alcance de las graves tensiones ideológicas de la segunda mitad del siglo XIX y primera del XX, que formaron notablemente los marcos de valores y crearon los acontecimientos sociales reales del entorno ruso. Fue una época en la que se produjo el enfrentamiento entre el pensamiento religioso y el secular. Este último es crucial, ya que describe la manifestación más dominante del pensamiento secular de la época, es decir, el populismo ruso (narodnismo). El artículo se enfoca en la rama revolucionaria del populismo ruso, cuya quintaesencia es P. N. Tkachev. Acercarse a los principales pilares conceptuales de las obras de Tkachev proporciona las bases para un análisis del posible impacto e influencia del populismo ruso radical en las acciones de una de las figuras más controvertidas no solo en la historia rusa, sino también en la historia de la humanidad como tal: Vladímir Ilich Lenin. También se esbozan posibles marcos y cuestiones relativas a la relación entre el populismo ruso y Lenin. El objetivo es estimular nuevos estudios críticos, histórico-filosóficos sobre el populismo ruso, así como sobre el legado genuino de Lenin. Sin embargo, se rechaza cualquier ideologización o excusa del leninismo.

$$
\text { শ্য }
$$

\section{P. N. TKACHEV, LENIN'S PREDECESSOR WITH(OUT) IMPACT}

ABSTRACT: The paper is set into the scope of dramatic ideological tensions of the second half of the 19th century and the beginning of the 20th century which notably formed the value frameworks as well as created real social events of the Russian environment. It was a time when the mutual confrontation between religiously and secularly oriented thinking took place. The latter is crucial since it describes the most dominant manifestation of the secular thinking of the period, i.e. the Russian Narodnism. The focus of the paper aims at the revolutionary branch of Narodnism, the quintessence of which is P. N. Tkachev. Approaching the main conceptual pillars of Tkachev's works provides the foundations for an analysis of possible impact and influence of the radical Narodnism on the actions of one of the most controversial figures not only in the Russian history

* Departamento de Educación Cívica del Instituto de Ciencias Políticas de la Facultad de Filosofía y Letras de la Universidad de Prešov, Eslovaquia. 


\section{ONDREJ MARCHEVSKÝ}

but also in human history as such - Vladimir Ilich Lenin. The paper also outlines possible frameworks and issues concerning the mutual relationship between Russian Narodnism and Lenin. The aim is to stimulate new critical, historical-philosophical studies of the Russian Narodnism as well as of the genuine legacy of Lenin. Nonetheless, I refuse any ideologizing or excusing the Leninism.

PALABRAS CLAVE: Filosofía rusa, populismo ruso, perspectivas, revolución, valores.

KEY WORDS: perspectives, revolution, Russian philosophy, Russian narodnism, values.

RECEPCIÓN: 25 de octubre de 2019.

APROBACIÓN: 18 de diciembre de 2019.

DOI: $10.5347 / 01856383.0132 .000298607$ 


\section{P. N. TKACHEV, EL PREDECESOR DE LENIN CON (SIN) IMPACTO*}

La doctrina populista ha sido — al menos en parterevivida en el leninismo. Tengo en mente la doctrina de Bakunin, Nechayev y Tkachev en particular.

Andrzej Walicki

La naturaleza del pensamiento filosófico, de la moral, de la ética y tal vez también de una conciencia cultural más amplia dentro de entornos concretos suele estar constituida por alguna confrontación dramática, un choque, pero al mismo tiempo por la cooperación continua de un espectro más o menos original de iniciativas. El pensamiento ruso puede verse como fuente rica de ejemplos, y principalmente el pensamiento de la segunda mitad del siglo XIX y primera del XX.

Es un periodo lleno de mensajes intemporales, cuyo significado resuena y resonará en la humanidad educada de todas las generaciones. Es también un periodo que dio origen a acontecimientos percibidos como grandes traumas de la historia rusa y también de la historia mundial, entre los cuales la Revolución Rusa de 1917 es el más delicado.

Junto con las obras de Soloviov, Dostoyevski, Tólstoi, Chéjov, Berdiáyev, Florenski o Ilyín, se puede ver también el desarrollo de un pensamiento estrictamente secular, cuyo objetivo es un cambio en Rusia, un cambio decidido y rápido, el revolucionario. Se encarna en las obras de los pensadores populistas ${ }^{1}$ y más tarde en las actividades de Lenin.

* El documento es el resultado del proyecto de investigación VEGA 1/0231/18 El drama de la libertad en el pensamiento filosófico ruso del siglo XX. Traducción del inglés de Carlos Gutiérrez Lozano. El traductor agradece cordialmente la ayuda de Fedor Shchipitsyn en la traducción de los términos rusos.

${ }^{1}$ El populismo ruso es un movimiento secular que solía llamarse también "inteligencia populista". Con una influencia considerable en los cambios sociales y políticos, representa una 
Hablar de Lenin — principalmente en los países del bloque del Esterequiere un grado considerable de "gracia" y "tacto" profesional. Es un hecho que las heridas - y no solo las físicas - son muy profundas, y que en lo que respecta a Lenin, no es posible evitar opiniones que impliquen desconfianza o miedo y también animosidad, desprecio, incluso repugnancia. Es importante señalar que todos los sentimientos mencionados son totalmente legítimos. Por esta razón, me gustaría dejar claro que mi objetivo no es justificar o glorificar el pensamiento ruso radical. Abordo el espectro radical del pensamiento ruso como cuestión histórico-filosófica que debería reflexionarse críticamente. No podemos simplemente cerrar los ojos o adoptar la actitud de ignorar el tema como una especie de "castigo". Al hacerlo, solo repetiríamos los pecados de aquellos a quienes criticamos por lo mismo. Y nuestra actitud no sería menos radical que la de ellos. Una crítica legítima debe basarse en el

de las formaciones intelectuales más influyentes de la segunda mitad del siglo XIX en Rusia. Los comienzos de este movimiento están relacionados con acontecimientos como la muerte del emperador Nicolás I (1855), la caída de Sebastopol durante la guerra de Crimea (1856) o la abolición de la servidumbre en Rusia (1861). La cuestión del fin del populismo ruso está abierta. Se aprecian diferentes cambios para tener en cuenta, como el intento de asesinato del emperador Alejandro II (1881), la caída de Port Arthur (1905) en la guerra ruso-japonesa o los acontecimientos de 1918. Sin embargo, un análisis de las actitudes populistas nos permite encontrar un conjunto de temas característicos y analizados frecuentemente: el interés y el cuidado de la gente, el sentido de culpa y la deuda moral con respecto a la gente, la voluntad de redimir la deuda, la intención de trabajar por el bien de la gente. Con respecto al populismo ruso como un movimiento de extraordinaria riqueza, se pueden definir algunos aspectos del fenómeno populista a través de los cuales es posible examinarlo y problematizarlo. En primer lugar, podemos mencionar la relación del populismo ruso con la gente. A aspectos importantes del examen pertenece el estudio del populismo ruso como movimiento político-teórico e ideológico. El populismo ruso como movimiento práctico puede ser percibido en dos niveles. En el primero, es la ilustración pública, también llamada el caminar entre la gente (1872-1875). El segundo puede identificarse con anarquismo, terrorismo, revolución. El populismo ruso también se refleja como un movimiento económico, una utopía, un movimiento ético, un movimiento literario, periodismo, pensamiento filosófico. Para más detalles, véase Zverev, Русское народничество [“Е1 nacionalismo ruso"], 2009, Moscú, RAST Publishing House; M. Broda, Narodnickie ambiwalencje. Międzi apoteoza ludu a terorem ["Ambivalencias nacionales. Entre la apoteosis del pueblo y el teorema”], 2003, Łodź, Proszyński i S-ka; P. Pomper, The Russian revolutionary intelligentsia, 1993, Wheeling, Harlan Davidson; W. Rydzewski, Filozofia polityczna rosyjskiego narodnictwa ["Filosofía política de la nación rusa"], 1988, Cracovia, Ediciones de la Universidad Jagelónica; A. Walicki, Zarys Myśli Rosyjskiej od Oświecenia do Renesansu ReligijnoFilozoficznego ["Bosquejo del pensamiento ruso desde la Ilustración hasta el renacimiento religioso-filosófico”], 2005, Cracovia, Ediciones de la Universidad Jagelónica. 
conocimiento del contenido criticado, así como en las circunstancias de su configuración. Así, las siguientes líneas están escritas para contribuir al conocimiento del fenómeno, no para excusar o racionalizar enfermedades y patologías históricas.

Naturalmente, el alcance de este artículo no es suficiente para una comprensión compleja de una cuestión tan delicada. Por esta razón, es necesario especificar mi punto de vista con más detalle.

Como indica el epígrafe de Andzrej Walicki, entre los pensadores populistas radicales el estatus importante está en manos de Piotr Nikitich Tkachev. ${ }^{2}$ La cita de Walicki también muestra que existían

\begin{abstract}
${ }^{2}$ Tkachev (Sivtsov, provincia de Pskov, 1844-París, 1886) fue hijo de un conocido arquitecto que murió cuando Piotr tenía siete años. A continuación, junto con su madre, dos hermanas y un hermano, se trasladaron a la capital, San Petersburgo. La intención de la madre era asegurar una educación de calidad para sus hijos. Como estudiante, Tkachev se interesó extraordinariamente en las actividades de Garibaldi. Al terminar la escuela, continuó sus estudios en la Facultad de Derecho de la Universidad de San Petersburgo (1861). Ahí comenzó a expresar sus opiniones críticas de la sociedad. Sus actividades eran tales, que pasó dos meses en prisión durante el otoño de 1861. Tkachev confiaba en la ilegitimidad de su encarcelamiento detrás de los muros de la fortaleza de Kronstadt. Como señaló Isakov ["Pyotr Niktich Tkachev", en P. N. Tkachev, Obras selectas, 2010, Moscú, Rosspen, pp. 5-35], ese incidente sembró las semillas de su radicalización. A consecuencia de su condena, Tkachev fue expulsado de la universidad y se decidió por una intensa educación autodidacta. Terminó sus estudios extramuros y defendió su tesis sobre la reinserción de delincuentes menores de edad. Se ganaba la vida como auxiliar en el tribunal de justicia, donde obtuvo suficiente material para una evaluación del sistema legal y judicial en Rusia. Allí sentó las bases de su debut literario, que tuvo lugar en 1862 en la revista Время [“Tiempo"], editada por los hermanos Dostoyevski. Para entonces, la censura ya había prohibido tres artículos de Tkachev, una tacha que no hizo sino estimularlo. Estaba convencido de que era una señal de que escribía sobre algo peligroso para el punto de vista del poder oficial, algo que podría cambiar las condiciones vigentes. Comenzó a cooperar también con otros consejos editoriales y publicó sus artículos en revistas comо Библиотека для чтения [“Biblioteca de Lectura"], Русское слово ["Palabra Rusa"] y más tarde Дело ["Negocio"]. Aparte de las cuestiones políticas y económicas, Tkachev se ocupó también de cuestiones de derecho, estadística, emancipación de la mujer, crítica literaria o historia. Sus artículos tuvieron una gran respuesta en toda Rusia. Gracias a sus conocimientos de alemán, francés e inglés (producto de su autodidactismo) se enteró de opiniones y actitudes diferentes de los intelectuales de la época. También trabajó en muchas traducciones comentadas, lo que enriqueció su medio intelectual. Era una persona extraordinariamente activa que dedicaba mucho tiempo al trabajo, la escritura o la traducción, y que también se dedicaba a la vida política y a su espectro radical en particular. Como consecuencia, Tkachev estaba constantemente bajo la supervisión de la policía y caía en la cárcel por breves periodos. Por su participación en círculos radicales, fue reubicado en la provincia. Desde allí huyó a Suiza en diciembre de 1873. Durante su exilio, intentó unirse a Piotr Lavrov, pero muy pronto descubrió que sus opiniones eran diametralmente diferentes y que sería imposible que colaboraran. Después de sus polémicas con Lavrov y con Engels, Tkachev decidió establecer su propia imprenta para
\end{abstract}


conexiones histórico-filosóficas y sociopolíticas entre el pensamiento populista y las actitudes de Lenin. En este artículo se presentan los resultados parciales de mi investigación sobre estas conexiones. La primera parte es una reflexión sobre los escritos originales de Tkachev. Acudí a las fuentes originales para exponer las conceptualizaciones de Tkachev sobre la revolución como cambio radical, la comprensión de la sociedad, el ser humano, la acción y el progreso en la historia.

En la segunda parte se aborda el problema de la posible conexión ideológica entre el legado populista, y en particular las opiniones de Tkachev, y el legado y las obras de Vladímir Ilich Lenin. Este examen dará como resultado un bosquejo de los horizontes y visiones actuales con respecto a la investigación de la línea que va del populismo ruso a Lenin. Partiré del trabajo Idea wolnośći u myślicieli rosykskich [“"La idea de la libertad para los pensadores rusos"] de Andrzej Walicki, ${ }^{3}$ y del segundo volumen del opus magnum de Leszek Kołakowski, Las principales corrientes del marxismo. ${ }^{4}$ Así, me remito a las obras de los historiadores a quienes considero precursores de una nueva lectura de la historia del pensamiento ruso. A pesar de que las posturas de estos historiadores no son complejas, son tan originales que podrían constituir un punto de partida (no el último) de nuevos exámenes en este campo de estudio.

difundir sus ideas. Sus actitudes fueron recibidas positivamente por el círculo eslavo rusopolaco, que tenía opiniones similares a las de los blanquistas franceses. La asociación publicó la revista Nabat desde finales del año 1875 en Ginebra y desde 1879 en Londres. Tkachev se convirtió en el principal ideólogo y figura central no solo del consejo editorial y de la revista, sino también del fuerte Movimiento Secreto de Liberación Nacional, que luchó por el derrocamiento del régimen zarista y por la revolución en Rusia. Las actividades de Tkachev atrajeron constantemente la atención de la policía rusa, que controlaba toda su comunicación con el entorno nacional e informaba de los resultados al propio zar. En 1878 Tkachev dejó el consejo editorial de la revista Nabat y cedió su puesto a Kaspar Turski, un fiel seguidor polaco, para trasladarse a París. Durante su estancia en Francia hizo realidad uno de sus sueños en 1879, cuando se reunió personalmente con Blanqui, que acababa de salir de la cárcel. Sin embargo, no estaban destinados a una larga amistad, porque Blanqui murió menos de dos años después, en enero de 1881. Tkachev iba a ser uno de los oradores principales en el funeral, pero fue arrestado y se frustró su intención de despedirse de su gran ejemplo. En 1882 comenzó a sufrir problemas mentales graves que lo llevaron a la muerte cuatro años después.

${ }^{3}$ Andrzej Walicki, Idea wolności u myślicieli rosyjskich, 2000, Cracovia, Editorial de la Universidad Jagelónica.

${ }^{4}$ Las principales corrientes del marxismo. II: La edad de oro, 1982, Madrid, Alianza, trad. de Jorge Vigil. 
En primer lugar, cabe señalar que en el caso de todos los autores populistas, uno de los estímulos fundamentales de sus reflexiones filosóficas es la noción de la necesidad de un cambio de las condiciones sociales existentes en Rusia en la segunda mitad del siglo XIX. Se pueden encontrar varias reflexiones sobre la revolución y el golpe violento, y también sobre el derrocamiento del zar y la autocracia zarista. Sin embargo, ni para N. K. Mijailovski ni para P. L. Lavrov este motivo es tan decisivo como para Tkachev. Él aborda la revolución como la revolución social y la define de la siguiente manera: "Un cambio radical de las relaciones sociales y morales de los miembros de la sociedad se llama revolución social". ${ }^{5}$ En este contexto, sería apropiado mencionar lo que Tkachev entendía por anarquía: "Anarquía significa un no reinado. Pero un no reinado es solo una de las consecuencias lógicas necesarias de una causa mucho más profunda y fundamental: la igualdad". ${ }^{6}$ En la siguiente página de la misma obra, Tkachev continúa:

Igualdad presupone anarquía, mientras que anarquía presupone libertad. Sin embargo, tanto igualdad como libertad - ambos conceptos se encuentran en un solo término, en una sola palabra - en la palabra fraternidad. Donde hay fraternidad, también hay igualdad, donde hay igualdad, también hay no reinado y también hay libertad. ${ }^{7}$

Ahora tenemos una idea de los puntos de partida de Tkachev. Para terminar, cito su definición de socialismo: "El socialismo es una definición socialista de las relaciones sociales. Es una definición derivada de un examen científico coherente y un análisis crítico de los fenómenos de la vida social, y es tan general y válida como cualquier teoría matemática". ${ }^{8}$ Cito esta vaga definición de socialismo sin una explicación más clara porque muestra un rasgo característico que acompaña

${ }^{5}$ Pjotr N. Tkachev, "Революция и принцип национальности” [“Revolución y el principio de nacionalidad”] en Избранное [“Obras selectas”], 2010, Moscú, Rosspen, p. 651.

${ }^{6}$ Pjotr N.Tkachev, "Набат (Программа журнала)" [“Nabat (Programa de revista)”], en Ibid., p. 457.

${ }^{7}$ Ibid., p. 458.

${ }^{8}$ Tkachev, "Revolución y el principio de nacionalidad”, p. 660. 
el pensamiento de Tkachev. Me refiero a su énfasis en el análisis científico y crítico, cuyos resultados son generalmente válidos. Así, si Tkachev habla de la necesidad del cambio, ve las posibilidades y el espacio para el cambio como siempre presentes. Destaca varias veces que la posibilidad del cambio está presente también en la situación o en el entorno en el que el statu quo duraría incluso mil años. Un estado a largo plazo sin cambios no significa que sea inmutable y válido para siempre. Debe ser percibido como un símbolo que indica que ciertas circunstancias no han cambiado. Como afirma Tkachev:

Los ideales sociales corresponden a las formas de convivencia social que los forman. Si las formas de convivencia social son conservadoras, si no se puede encontrar ningún impulso interior para un mayor desarrollo, los ideales estarán marcados también por el mismo carácter conservador. Y en verdad, el ideal social de nuestra nación no excede las formas petrificadas de su modo de vida. ${ }^{9}$

He elegido esta idea para ilustrar cómo percibe Tkachev su época. La idea, así como el autor, atañe también al problema de determinar los ideales sociales por las formas existentes de convivencia social. Volveré sobre el análisis de este motivo más adelante.

En cuanto al legado del pensamiento de Tkachev, es necesario señalar su énfasis en un cambio radical, no solo en el sentido de hacer hincapié en la velocidad del cambio, sino también en un marco de significado mucho más amplio. En su opinión, el cambio radical implica una organización social radicalmente diferente a la existente, que podría constituirse inmediatamente después de la violenta toma revolucionaria del poder. Debe ser una organización anarquista de la sociedad. Las opiniones de Tkachev sobre una sociedad radicalmente diferente aparecen en el contexto de la polémica con dos proyectos anarquistas de organización de relaciones sociales formulada por el círculo de socialistas de Ginebra y Bruselas. No me referiré en detalle a estos proyectos, ya que para una comprensión más clara de la posición inicial de Tkachev basta

${ }^{9}$ Tkachev, “Народ и революция” [“El pueblo y la revolución”], en ibid., p. 529. 
con mencionar que duda de su carácter anarquista porque ambos solo intentan dar un nuevo contenido o incluso un nuevo atuendo o uniforme a las viejas instituciones como el Estado, la policía, el ejército, el poder judicial, el gobierno. Según Tkachev, eso no es anarquía. La anarquía no puede considerar al Estado como una necesidad en cuanto a la organización de las relaciones sociales.

Dada esta problematización de la revolución como el camino necesario para un cambio de organización social, voy a hacer una incursión más amplia en este ámbito del pensamiento de Tkachev. Estoy convencido de que de esta manera se abre un espacio más claro para la comprensión de sus reflexiones filosóficas y de su legado como tal.

Detenernos en el grupo, la sociedad y la cuestión del ser humano ofrece los motivos cruciales que deben ser abordados en esta parte de mi consideración de la filosofía de Tkachev.

Al referirse a los términos "grupo" y "sociedad", es apropiado recalcar que Tkachev usa estos términos con varios significados. Por "grupo" o "minoría", o más precisamente, "minoría revolucionaria", Tkachev entiende ese poder que debe establecer una revolución. "Nosotros decimos: Una revolución tiene que ser implantada por una minoría más o menos inteligente y revolucionaria". ${ }^{10}$ Un iniciador, líder y sujeto del fermento revolucionario debe ser una minoría, cuya identidad Tkachev encuentra en el medio de los intelectuales. Esta parte de la sociedad tiene una educación, está "dotada", y tiene conocimientos y capacidades para comprender un proceso revolucionario. En otro lugar de los escritos de Tkachev podemos encontrar la idea que se refiere al problema de una minoría revolucionaria, lo que nos permite tener una mejor idea de lo que le importa a Tkachev: “¿Cuándo entenderemos finalmente que solo una organización unificada, disciplinada y muy serena puede alcanzar el poder genuino, que solo de esta manera podemos compensar nuestro pequeño número en una medida suficiente?". ${ }^{11}$ Tkachev especifica la mentalidad de una minoría revolucionaria de la siguiente manera: "Para cambiar la nación de un posible poder revolucionario a un

${ }^{10}$ Tkachev, “Революция и государство" [“La revolución y el Estado”], en ibid., p. 515.

${ }^{11}$ Tkachev, "Наши иллюзии” ["Nuestras ilusiones”], en ibid., p. 505. 
poder genuino, nosotros (la minoría revolucionaria), en primer lugar, tenemos que desvitalizar, debilitar y destruir la organización política que devasta a la nación y también al Estado conservador, explotador y absolutista". ${ }^{12}$ Por lo tanto, Tkachev lo ve como la única solución, como la única salida sin otras opciones. La noción de la solución única representa una herramienta argumentativa que Tkachev menciona a menudo cuando presenta sus opiniones y, como veremos adelante, incluso abusa de ella conscientemente, aunque sin exagerar. Formulo esta tesis aquí, entre las afirmaciones iniciales, ya que estoy convencido de que una inmersión más profunda en el pensamiento filosófico de Tkachev confirmará plenamente mi evaluación, principalmente en el contexto del criterio de obviedad que analizaré más tarde.

Cuando Tkachev escribe sobre la necesidad de derrocar al Estado conservador, apela a la autoridad de la historia, que para él representa la base de la argumentación y, por otro lado, también la cuestión clave a la que intenta hacer frente: "Si las evidencias a priori son insuficientes, consideremos la historia. Examinemos los movimientos puramente populares - de la gran revuelta de los esclavos en Roma a la Comuna de París - y veremos que todo esto, sin excepción, solo ocurre cuando el caos y el desorden reinan en los altos círculos sociales". ${ }^{13}$ De esta manera, Tkachev formula su convicción sobre la necesidad de una lucha revolucionaria y su momento oportuno en el contexto contemporáneo ruso.

Por "sociedad", Tkachev entiende, en primer lugar, el grupo objetivo. El espacio social es un lugar que hay que cambiar. Por lo tanto, no es el ser humano el que tiene un lugar activo insustituible en el proceso revolucionario y, por consiguiente, no es el ser humano el que debe cambiarse a sí mismo por sí mismo. Tkachev insiste en la necesidad de cambiar la sociedad, pues solo el cambio es determinante para el ser humano como individuo. Esta visión también se corresponde con su comprensión del ser humano como tal. A modo de ejemplo, podemos mencionar su punto de vista sobre las diferencias radicales entre los esfuerzos,

${ }^{12}$ Ibid., p. 509.

${ }^{13}$ Loc. cit. 
objetivos y actividades de los socialistas, los sectarios religiosos y los revolucionarios. ${ }^{14}$

El papel del primero, si puedo decirlo así, tiene un carácter puramente individual: un sectario trata de educar, de transformar, de mejorar a cada uno por separado. Un socialista revolucionario intenta cambiar y transformar las condiciones sociales que influyen en la vida y el desarrollo de toda la sociedad mientras permanece en la posición del individuo. El primero influye en el individuo, el segundo influye en las masas. ${ }^{15}$

Así, Tkachev apunta a un cambio del individuo por medio del cambio de las circunstancias sociales en las que el individuo vive y se desarrolla a sí mismo. Debe insistirse en que, al hacerlo, Tkachev no subestima el valor del ser humano como tal; no considera que el ser humano sea inferior a la totalidad y que la totalidad tenga primacía. La totalidad, la sociedad, es una herramienta importante. En el contexto de estas reflexiones, permítaseme señalar que, a pesar de que el proceso de transformación no se basa predominantemente en la actividad del individuo, los cambios sugeridos por Tkachev están destinados principalmente a beneficiar a todos los seres humanos. Esto tendrá un impacto esencial también en las reflexiones que abordaré más adelante. Según Tkachev, no solo debe realizarse una revolución por iniciativa de la minoría, la minoría revolucionaria, sino que también es decisiva para todo el desarrollo que siga a la revolución. La situación debe consolidarse por obra de una pequeña minoría competente, ordenada jerárquicamente y estabilizada, un grupo dominante con objetivos claros.

La minoría revolucionaria tiene que trabajar en el ocultamiento perfecto antes de que estalle la revolución. Enseguida, Tkachev intenta señalar la necesidad de formar organizaciones y estructuras que gestionen este proceso, como la unión socialmente revolucionaria, el partido. Al pensar en esta minoría dominante como un grupo bien organi-

${ }^{14}$ Con el término "sectario religioso" Tkachev designa a los seguidores de la filosofía religiosa rusa que representaban la mayor oposición ideológica y filosófica al populismo ruso como corriente de pensamiento secular. Podemos mencionar a Vladímir Sergeievich Soloviov como ejemplo del pensamiento religioso ruso en la segunda mitad del siglo XIX.

${ }^{15}$ Tkachev, "Revolución y el principio de nacionalidad", p. 651. 
zado, Tkachev es consciente de las críticas de los opositores dirigidas a un posible abuso de poder por parte de la minoría. Este contexto se relaciona con un extenso tema de los escritos de Tkachev, el tema del partido revolucionario, elaborado principalmente en la obra ¿Qué es el partido del progreso?. El alcance de este artículo no me permite exponer más ampliamente este motivo. Mencionaré solo algunos aspectos relevantes para el tema, es decir, cuáles son los fundamentos sobre los que debe realizarse el cambio social revolucionario.

Cuando hablamos de la cuestión de un cambio de sociedad mediante un golpe revolucionario, debemos prestar atención también a la idea que tiene Tkachev del ser humano. Como dije, en opinión de Tkachev un ser humano individual no representa ningún papel protagónico. Se puede ver también en el uso libre de los términos "ser humano", "individuo" y "persona" en sus obras. La noción de que el ser humano es un producto de la sociedad y de su entorno puede considerarse como el atributo dominante de las características del ser humano:

El yo humano es producto de una larga secuencia de causas; depende plenamente del entorno en el que vive. Está conectado por lazos ininterrumpidos con muchos otros yos humanos que le han precedido y de los que es contemporáneo y que determinan su acción. En resumen, es solo uno de los pequeños eslabones de una cadena interminable de causas y consecuencias. En otras palabras, representa una de las manifestaciones de esa necesidad, que en el pasado era lo contrario de la libertad. ${ }^{16}$

Así, Tkachev subraya la influencia de la sociedad en el individuo de tal manera que la sociedad no solo determina al ser humano, sino que incluso determina cómo un ser humano se percibe a sí mismo dentro de categorías tales como la libertad de acción y de pensamiento:

Nuestra conciencia de la propia libertad de pensamiento y acción no es más que la conciencia de que todo nuestro pensamiento y acción depende y está determinado por nuestro yo, es decir, un conjunto de esas diversas

${ }^{16}$ Tkachev, "Роль мысли в истории" ["El papel del pensamiento en la historia”], en Кладези мудрости российских философов. Из истории отечественной философской мыслл ["Las fuentes de sabiduría de los filósofos rusos. De la historia del pensamiento filosófico ruso"], 1990, Moscú, Pravda, p. 140. 
causas físicas y psíquicas, esos estados afectivos e intelectuales que hemos acordado llamar nuestro yo, nuestro carácter, nuestra voluntad, etc. ${ }^{17}$

Otro atributo principal del ser humano es su naturaleza egoísta: "La mayoría de las personas, en la mayoría de los casos, no actúa sobre la base de principios nobles o ideas abstractas, sino sobre la base de un cálculo ordinario". ${ }^{18}$ En otro lugar, observa con el mismo espíritu: "Si percibiéramos al ser humano por separado, aislado de los demás, sería innegable que cada ser humano siempre piensa y actúa en función de sus intereses privados, para su ventaja, en su propio beneficio, en su propio bienestar. Esto representa el único estímulo de la actividad humana". ${ }^{19}$ Después agrega el segundo lado, el social, del ser humano: "Para confirmar la veracidad del utilitarismo humano, es apropiado mirar los resultados del impacto de toda la sociedad entendida como una conexión de muchos individuos humanos" ${ }^{20}$ El resultado de estas afirmaciones es la siguiente pregunta: “¿De dónde viene esa contradicción peculiar entre el esfuerzo individual de cada ser humano por alcanzar la felicidad personal y las consecuencias de la influencia de la sociedad que se oponen directamente a toda felicidad personal?"21 Tkachev escribe que la mayoría de los filósofos y teólogos respetados han explicado este asunto por una influencia externa, por la influencia de algún poder fuera del ser humano. De esta manera, la cuestión se transforma en el problema eterno, que se explica solo aparentemente por las concepciones individuales, incluida la religión. Tkachev no está en absoluto de acuerdo con esta explicación y afirma que la cuestión puede resolverse en un nivel de validez general. Sin embargo, al hacerlo, no niega que no es solo una acción humana intrínseca. Esa convicción o, más precisamente, esa demanda formulada de validez general desempeñará un papel importante en la formulación de las ideas posteriores de este pensador populista.

${ }^{17}$ Ibid., p. 141.

${ }^{18}$ Tkachev, “Очерки из истории рационализма" [“Ensayos de historia del racionalismo”], en Сочинения B 2-x Томах. Том 1 [“'Obras en dos tomos, tomo 1”], Moscú, Pensamiento, p. 130.

${ }^{19}$ Ibid., p. 120.

${ }^{20}$ Loc. cit.

${ }^{21} I d$. 
El motivo de la acción y la decisión en la acción representa otra característica fundamental en el pensamiento de Tkachev, lo que probablemente no es de sorprender si tenemos en cuenta las ideas anteriores. Es comprensible o es posible suponer que el autor que pone tanto énfasis en el cambio de organización social de una manera radical, recalcará ese motivo. Echemos un vistazo a su respuesta a la pregunta sobre el papel del ideal moral y la necesidad de su aplicación:

La moralidad de cierto ambiente no está determinada solo por la extensión, el sentido y la humanidad de sus ideales morales, sino principalmente (y eso es fundamental) por su relación con estos ideales. El ser humano puede tener un ideal moral amplio y significativo, pero si ni siquiera mueve un dedo para su aplicación práctica, si no lo aplica en su vida, si no lo proyecta en su acción en la sociedad, nadie lo considerará moral. ${ }^{22}$

Podemos notar que aquí Tkachev se refiere al ser humano como individuo. Sin embargo, he escogido esta idea principalmente como ilustración del motivo de la acción. La idea es interesante también porque, por un lado, determina la necesidad de una acción decisiva, pero por otro lado, como intentaré demostrar, el motivo de la acción y la aplicación de un ideal abre un espacio problemático para Tkachev. Según el pensador ruso, es crucial responder a la pregunta que puede formularse de la siguiente manera: ¿Qué ideal debe cumplirse, según el cual debemos actuar? Por lo tanto, Tkachev está interesado en lo que debe poner en marcha un revolucionario. En concreto, Tkachev está en cierto modo angustiado por la noción de muchos ideales que podrían imaginarse y también por el hecho de que un ideal cualquiera puede no ser el único ni el correcto. Tkachev, que hace hincapié en el principio de la validez general y la necesidad, ve en ello no solo un problema, sino también el error esencial. Un problema que acompaña a esta relatividad es la frecuente concentración excesiva en la cuestión de cómo justificar y deter-

${ }^{22}$ Tkachev, “Литературные мелочи” [“Minucias literarias”], en Кладези мудрости российских философов. Из истории отечественной философской мысли ["Las fuentes de sabiduría de los pensadores rusos. De la historia del pensamiento filosófico ruso"], Moscú, Pravda, p. 449. 
minar los ideales correctos, que según Tkachev no conducen a ningún resultado y producen un círculo vicioso de cuestionamiento constante sin posibilidad de llegar a una idea clara de lo que debe ser puesto en marcha. No es difícil imaginar que entre las intenciones de las obras de Tkachev, este asunto sea extraordinariamente serio si tomamos en consideración lo que tanto recalca. Según Tkachev, el valor de los ideales reside principalmente en su papel de objetivos de acción e implantación de cambios.

Hasta ahora he intentado introducir aquellos elementos y cuestiones que influyeron en gran medida en las opiniones de Tkachev y que surgen de la necesidad de llevar a cabo un cambio social radical en forma de una revolución social emprendida por un pequeño grupo de revolucionarios, es decir, de ajustar las condiciones sociales sobre la base de determinaciones generalmente válidas para influir en el individuo. Podemos imaginar las causas del problema, más allá de las afirmaciones de Tkachev. Sin embargo, hay que recordar que el interés central de este trabajo reside únicamente en las obras y opiniones del pensador ruso. La siguiente afirmación puede ser entendida como un hito en la lectura de las obras de Tkachev:

La preparación de una revolución no es papel de un revolucionario. La preparan los explotadores: capitalistas, terratenientes, papas, policías, oficinistas, conservadores, liberales, progresistas, etc. El revolucionario no solo tiene que usar y combinar adecuadamente los elementos que son completados, dados, creados por la historia, y que emergen de la vida social de una nación, que se consolidan y desarrollan gracias a la terquedad de los protectores y al sinsentido de los gobiernos con sus policías y ejércitos [...] El revolucionario no prepara una revolución, la pone en práctica. ¡Sigamos adelante! ¡Vamos, deprisa! Toda indecisión, cada retraso es criminal. ${ }^{23}$

La base de una revolución ilustrada en representaciones de determinaciones sociales cubiertas por el motivo de capitalistas, terratenientes, papas, policías o funcionarios públicos, es, como supongo, bastante comprensible. Considero que la idea dada es un hito en la lectura por la

${ }^{23}$ Tkachev, "Nabat”, p. 455. 
razón de que un revolucionario no es el que prepara una revolución, sino que "solo" la pone en marcha, y lo hace con la ayuda de cierto conjunto de instrumentos que aún no conocemos. En este momento, la tarea inspiradora puede cristalizarse más claramente en el trasfondo de una exigencia que Tkachev formula de la siguiente manera: "¿Qué determina, en general, los poderes revolucionarios de tal o cual entorno social? Están determinados principalmente por dos requisitos: por el carácter de los ideales en un entorno dado, por un lado, y por su relación con la realidad de la vida real, por otro". ${ }^{24}$ Aquí podemos encontrar una noción más detallada de la necesidad de determinar un ideal que debe ser materializado ya que representa la determinación fundamental de la acción como la actividad dominante. El segundo aspecto que enriquece nuestras reflexiones sobre la obra de Tkachev es la relación con una realidad actual. Por tal Tkachev entiende la relación con lo que de hecho sucede en la sociedad. Una misión inspiradora de quienes preparan una revolución es la de determinar el ideal y encontrar los instrumentos para llevar a cabo los cambios en la sociedad con el fin de satisfacer las necesidades sociales. Tkachev señala frecuentemente el problema de la separación de las concepciones del pensamiento de la vida real. En consecuencia, solo contribuye (además de a la ausencia de una validez general de los ideales) a la imposibilidad de actuar de acuerdo con ellos. La importancia del criterio de arraigar el pensamiento en la acción social y sus necesidades, así como la aplicabilidad en este entorno, queda ilustrada también por la siguiente idea: "Es comprensible que entre todos los escritos, los más importantes para nosotros sean los que aclaran a la juventud sus ideales revolucionarios, los que le dan a la juventud consejos y ejemplos de una praxis revolucionaria, los que tratan cuestiones básicas de su actividad de una u otra manera". ${ }^{25}$ Estos escritos forman uno de los marcos básicos dentro de los cuales Tkachev presenta sus ideas. De hecho, tiene la indudable ambición de entrar en este espacio y ocuparse del uso práctico de las ideas en el entorno revolucionario y posrevolucionario del segundo día después de la revolución, cuando las

24 “El pueblo y la revolución", p. 527.

25 "El papel del pensamiento en la historia", p. 174. 
relaciones sociales se consolidarán de nuevo. La urgencia de estos requisitos en el momento en que Tkachev estaba escribiendo se expresa en esta declaración:

Un revolucionario aún no se ha dado cuenta de cómo y por qué se requiere el remplazo de la organización anormal de las relaciones sociales existente, todavía no ha imaginado ningún ideal de un futuro luminoso. Hasta ahora, es imposible esperar resultados extraordinariamente útiles en su acción, no se puede ver ninguna manifestación de estabilidad, ni coherencia ni determinación. ${ }^{26}$

Estabilidad, coherencia, determinación representan las piedras angulares de los posibles cambios y la acción de un revolucionario que, sin embargo - hasta ahora - no se han cumplido, y un revolucionario mismo es incapaz de hacerlo porque no es su ámbito de actividad. Un revolucionario espera las metas que tiene que cumplir y también las herramientas con las que las cumplirá.

Para definir un contexto más amplio en el que se sitúan los pensamientos filosóficos de Tkachev, principalmente en la historia, considero necesario introducir las opiniones del autor en dos, o más precisamente, tres mutuamente interconectados niveles temporales en relación con el acto de la revolución en sí.

En primer lugar, hay un periodo preparatorio que, por un lado, radica en el deterioro de la situación social hasta tal punto que el cambio mediante un revolucionario y, de hecho, por un violento golpe de Estado parece inevitable, y por otro lado, dentro del periodo mencionado, el cambio se forma como producto de la escalada de la situación social en el plano de la ideología, la filosofía, etc., lo que constituye la plataforma de la propia revolución. El segundo periodo se denomina acertadamente según el título de una de sus obras: En la víspera y el día después de la revolución. Es un periodo de puesta en marcha de la revolución en sí misma y, simultáneamente, de cambios que llegarán después de que la revolución haya terminado. Los cambios que se producen tras el derro-

${ }^{26}$ Tkachev, “Анархическое государство” [“Estado anárquico”], en Избранное [“"Obras selectas”], 2010, Moscú, Rosspen, p. 543. 
camiento del régimen existente son acontecimientos a largo plazo y, por este motivo, he esbozado la evolución del pensamiento de Tkachev en dos, o más precisamente, tres periodos. El propio Tkachev entiende la transformación radical de la sociedad como un proceso a largo plazo. Representa otro nivel de las objeciones de Tkachev a las concepciones de los socialistas de Bruselas y Ginebra. Según Tkachev, ellos no se ocupan de cómo llegará este cambio en la práctica. Parece que consideran que una nueva organización va a caer del cielo, como si ya estuviera dada, y obrara y cumpliera todos los ideales socialistas. Sin embargo, ni siquiera tienen una idea de cómo podría establecerse.

Si escribí sobre la necesidad de un ideal para la puesta en marcha de la revolución, es necesario notar que estas reflexiones de Tkachev están ligadas al contenido del término "progreso". La idea de progreso tiene para el revolucionario un significado principal dentro de la dirección de su acción.

También he mencionado que en la fase preparatoria de la revolución, además de las condiciones sociales, tienen también un papel significativo otros factores que Tkachev no delimita de manera clara; sin embargo, puede entenderse que son los que crean las condiciones para 24 la realización de la revolución. Las opiniones de Tkachev sobre la historia indican que la obra del historiador desempeña un papel en el proceso. Solo un historiador ${ }^{27}$ parece ser el que tiene una participación significa-

${ }^{27}$ En este contexto, la pregunta que queda abierta es quién debe ser exactamente ese poder, el elemento que determinará la dirección clara de un cambio revolucionario. Basado en mi estudio previo de las obras de Tkachev, es posible pensar también en filósofos, periodistas y escritores, además de los historiadores, que parecen ser la base más aceptable. La falta de claridad lleva a cuestionar si acaso Tkachev trató el tema en alguna de sus obras que no se conservaron. En relación con las obras de Tkachev, se pueden encontrar indicaciones a textos que se atribuyen a este populista у que no se conservan (como la obra Эстетическая критика на почве науки ["Crítica estética basada en la ciencia"]). También es muy posible que la pregunta sea una cuestión abierta que el pensador ruso pretendía problematizar más tarde. Hay varios lugares en las obras de Tkachev en los que declara que en el futuro elaborará una pregunta en obra aparte, que no llegó a escribir (podemos mencionar los temas de las obras Педагогика - родная дочка психологии ["Pedagogía: hija natural de la psicología”] о Издательская и литературная деятельность Благосветлова [“Actividad editorial y literaria de Blagosvetlov"]). Podemos asumir que solo el propio Tkachev hubiera podido determinar esta dirección revolucionaria. Esta nota a pie de página debe leerse como indicación de un problema al que me propongo hacer frente en el futuro. 
tiva en la fase preparatoria de un cambio, junto a la atmósfera social general. Su misión consiste en comprender y explicar adecuadamente las fases progresistas o regresivas de la historia, y también en definir lo que es el progreso como un ideal que el revolucionario debe poner en marcha. Tkachev detalla sus ideas sobre qué elementos comprende una reflexión sobre el progreso, es decir, qué tipo de reflexión podría llamarse progresista: "Señalé los elementos esenciales e inevitables del término progreso. Tiene que contener necesariamente la noción de un movimiento en una dirección determinada para el logro de un objetivo determinado. Movimiento, dirección determinada y objetivos, tales son los tres momentos principales del progreso". ${ }^{28}$ En este contexto, más adelante formula otra idea importante: "Si se necesita un movimiento, y si este movimiento va en la misma dirección estable, entonces examinamos este movimiento como progresista”. ${ }^{29}$ Lo señala en otro lugar: “¿Cuál es la noción de progreso? Es un producto metafísico de una visión teleológica del mundo. El progreso supone un movimiento intencionado, un desarrollo dirigido a la consecución de un resultado que se considera su criterio. Sin una noción sobre la meta es impensable una noción sobre el progreso" ${ }^{30}$ Como he señalado, Tkachev caracteriza solo aquellos elementos que crean el término progreso. Es necesario abordar el problema del objetivo y los criterios de movimiento en una dirección estable sin un objetivo determinado conscientemente o con un objetivo que no está claro. Tkachev, en cierto modo, explica la existencia del progreso sin la posibilidad de que pueda ser percibido como progreso independientemente de una meta clara. Al mismo tiempo, crea un espacio para la explicación de las interpretaciones existentes del progreso, ante las cuales asume una actitud crítica. Entre los momentos del progreso, es determinante la meta junto con el movimiento. Ambos criterios, ambos momentos, pueden asignar a un proceso el nombre de "progreso". Como veremos, esto tendrá un significado esencial para Tkachev, ya que considera que la determinación de la meta es tan peculiar que nadie la

${ }^{28}$ Tkachev, “Что такое партия прогресса” [“Qué es el partido del progreso”], en Избранное [“Obras selectas”], 2010, Moscú, Rosspen, p. 296.

${ }^{29}$ Ibid., p. 309.

${ }^{30} \mathrm{Tkachev}$, "Наука в поэзии и поэзия в науке" [“La ciencia en la poesía y la poesía en la ciencia"], еn Избранное [“Obras selectas”], 2010, Moscú, Rosspen, p. 249. 
ha tenido en cuenta en una acción real hasta ahora. Por lo tanto, lo que falta aquí es el momento de la discontinuidad del movimiento que se refiere a cierta secuencia de acontecimientos que, en el caso de Tkachev, aún no han comenzado. Volveré sobre estos motivos y trataré de exponerlos de manera detallada en el contexto de las transformaciones fundadas en las obras de Tkachev. Me gustaría subrayar que él entiende estos elementos como componentes objetivamente válidos del término "progreso", mientras que ve el movimiento en sí mismo como una acción consciente, una actividad. Aquí nos encontramos con un problema relacionado con la postulación de cierta validez objetiva de los elementos del término "progreso" que no está planteado ni examinado en detalle en ninguna parte. Parece que Tkachev presupuso que existe algo así como el progreso en sí, definido por aquellos atributos que deberían determinarlo como objetivamente establecido e independiente de las evaluaciones subjetivas. Como vimos, los elementos de dirección y meta también pueden entenderse como elementos que permiten el movimiento en cualquier dirección y, al hacerlo, hacen que este movimiento se convierta en progreso. Este punto trae consigo problemas considerables, ya que estas variables pueden consistir en diversos contenidos, dependiendo de los individuos o de sociedades determinadas de manera diferente. En esta variabilidad ve Tkachev uno de los temas más importantes del examen y el cambio social. El esquema principal del problema se puede resumir de la siguiente manera: El ideal de progreso es un estímulo inevitable para la acción, pero su contenido puede variar. Tkachev formula una de sus opiniones negativas sobre una idea vigente del proceso histórico de la siguiente manera:

La teoría de un movimiento en círculo es bastante sombría. Es terrible pensar en lo que la historia humana presenta hace mucho tiempo, contada en un cuento de hadas, que no se puede encontrar nada nuevo e inesperado, que el futuro será solo una restauración del pasado, que la gente está sentenciada a la obra de Sísifo, que la piedra de la civilización es impulsada hacia una abrupta cumbre de progreso, empinado solo para que ruede de nuevo hasta el fondo. ${ }^{31}$

${ }^{31}$ Tkachev, "Qué es el partido del progreso", p. 304. 
En relación con el término "progreso", Tkachev presta atención a un asunto que podría llamarse la cuestión del vacío de contenido del término "progreso". Tkachev escribe: "Hay pocas palabras en la vida diaria de una sociedad de las que se abuse tanto y tan a menudo como de la palabra "progreso". 32 Tkachev lo ve como un gran problema; según su opinión, este término ha sido vaciado en el discurso social, aunque tiene el estatus esencial en relación con los acontecimientos sociales, ya que representa una determinación fundamental para una división de la sociedad para aquellos que luchan por el progreso y aquellos que pueden ser llamados conservadores y rutinarios. Con base en este criterio, también se definen grupos de colegas combatientes y enemigos: las partes que proceden de cierta determinación de progreso (incluso si la otra parte las acusa de ser rutinarias y conservadoras) pueden definir libremente estos grupos debido al contenido ambiguo del término.

Tkachev menciona un ejemplo interesante referido a las tiendas de una ciudad. Si todas las tiendas fueran designadas solo por la misma palabra "tienda" (la usa como un paralelismo del término "progreso"), no sabríamos lo que se vende allí, y por lo tanto tendríamos que recorrerlas todas para comprar lo que necesitamos. El autor admite que después de un tiempo, aprenderíamos a orientarnos en las tiendas y las calles y sabríamos exactamente dónde comprar esto o aquello, y ya no tendríamos que ir a todas una y otra vez. El problema aquí es que cada uno se llama a sí mismo un luchador por el progreso, pero cada uno "vende" su progreso. Si nos orientamos, sabremos qué idea del progreso se proporciona en tal o cual "tienda" $y$, por lo tanto, podríamos visitarlas de acuerdo con nuestras preferencias. Sin embargo, hasta que no nos orientemos, una carnicería nos venderá su progreso de la misma manera que una tienda de telas el suyo. Esta venta de diferentes tipos de progreso puede costarnos mucho tiempo y zapatos desgastados. Imaginemos — advierte Tkachev— que alguien tiene que trasladarse entre varias ciudades durante varios días consecutivos y que necesita ir de compras en todos esos lugares. Tkachev señala también una situación en la que se pediría un artículo en la tienda donde no se vende,

${ }^{32} I b i d .$, p. 277. 
y lo enviarán a una tienda equivocada, ya sea conscientemente o por tontería; por ejemplo, lo enviarían a la carnicería a comprar un abrigo. Tkachev quiere decir que incluso estos "traficantes" no tienen que conocerse entre sí. Tkachev dice que este problema puede volvernos locos y que afecta a todos los que quieren evaluar a la gente por la categoría de progreso, en otras palabras, dividirla en progresistas y conservadores, porque no está claro qué marcas de productos prefieren, dónde compran y hasta qué punto conocen la oferta local.

De esta manera, Tkachev señala el problema de una definición del término progreso que se convierte solo en la forma vacía de comunicación y se le puede atribuir una escala arbitraria de contenidos. Es necesario poner fin a esta ambigüedad de una vez por todas. Es necesario para que fructifiquen los esfuerzos revolucionarios. Al salir de un estancamiento peligroso y demencial, el pensador populista proporciona un criterio que debe aplicarse para determinar una visión clara —en la opinión de Tkachev—y objetivamente válida del progreso.

El criterio es la obviedad:

Y tal criterio existe y no es ningún fantasma o deseo. Sin embargo, ese criterio es obvio, no en ese sentido vulgar que tan a menudo se utiliza en la sociedad para expresar una convicción subjetiva ordinaria sobre la legitimidad, es decir, la veracidad de tal o cual cosa, sino en ese sentido más exacto, según el cual lo obvio denota algo que todo sujeto consideraría indudablemente convincente, es decir, verdadero, independientemente de sus opiniones. ${ }^{33}$

Esta es la tesis argumentativa fundamental de su concepción objetivamente válida que crea una base para otras explicaciones que conducen a los fundamentos de la acción de un revolucionario impaciente. Tkachev quiere explicar el carácter de ese algo: 34 "Estamos justificados para considerar que estos algos son verdaderos en sí mismos porque son verdad no solo para mí o para ti, sino para toda la gente en general. Y si

${ }^{33}$ Ibid., p. 285.

${ }^{34}$ Tkachev usa el equivalente ruso para algo en plural. 
la visión moral del mundo de un ser humano puede ser llevada a la inequívoca obligatoriedad para todos los sujetos, entonces no digas que es verdad solo para él, para ese ser humano concreto. No, es verdad en sí misma porque tiene que ser verdad para todos". ${ }^{35}$ De esta manera - para Tkachev clara (aunque para el lector ciertamente incomprensible)_, se ponen las bases para algos objetivamente válidos o existentes en general. Dado que los esfuerzos de Tkachev están orientados principalmente a la esfera de acción práctica, a la necesidad de transformación del país, no es ocioso y especifica esos algos objetivos como el hecho de la meta de progreso que, hasta ahora, se ha presentado como el elemento del término "progreso".

La meta se convierte en una necesidad en la vida de la sociedad: "La sociedad sin meta es lógicamente impensable, por lo que el hecho de que en la unión social ${ }^{36}$ esté siempre presente una meta es el hecho plenamente objetivo". ${ }^{37}$ En otro lado, Tkachev añade con un espíritu similar: "No podemos imponer objetivos a la naturaleza, pero sí podemos e incluso debemos hacerlo a la sociedad humana". 38

Posteriormente, tras la aclaración de los fundamentos objetivos del progreso, Tkachev formula una pregunta importante: "Si la vida humana tiene una meta objetiva que es obvia para todos, entonces ¿por qué esta meta es entendida de manera tan diferente por diversas personas?". 39 Incluso en este caso Tkachev ofrece una respuesta objetivamente válida, y por lo tanto "obvia":

Todos los pensadores (por supuesto, excluyendo a aquellos que investigan la sociedad como un organismo independiente que tiene sus propias unidades orgánicas) están de acuerdo en que la gente forma una sociedad para poder alcanzar sus objetivos humanos e individuales de una manera mejor y más completa. Por lo tanto, una unión colectiva de seres humanos no puede tener otra tarea que no sea la más completa y perfecta

${ }^{35}$ Tkachev, "Qué es el partido del progreso", p. 285.

${ }^{36}$ Tkachev utiliza este término con frecuencia, aunque no lo especifica. Eso indica que lo usa solo como un término general que denota sociedad.

${ }^{37}$ Tkachev, "Qué es el partido del progreso", p. 313.

${ }^{38}$ Tkachev, "La ciencia en la poesía y la poesía en la ciencia", p. 251.

${ }^{39}$ Tkachev, "Qué es el partido del progreso", p. 313. 
búsqueda posible de las metas existenciales de sus miembros. Todos también están de acuerdo en que estas metas vitales pueden quedar abarcadas por una meta: el esfuerzo de un ser humano para vivir una vida feliz, para alcanzar la felicidad. Según una opinión general, ese es el objetivo de la existencia humana. ${ }^{40}$

Aquí nos encontramos con un intento de proporcionar una explicación compleja y genuina de una validez objetiva que puede hacer frente a los pensamientos incómodos de una manera peculiar, ya sea dándolos a entender como fábulas subjetivas o metiéndolos en el rincón de las tonterías que no vale la pena comentar, porque sería desperdiciar el tiempo. Más tarde, nos encontramos con la noción de felicidad como meta objetiva: "La meta de la sociedad humana es idéntica a la meta del individuo, y eso es la felicidad humana. Esta meta puede ser llamada objetiva. Es evidente hasta tal punto que se hace obligatoria para la razón humana". ${ }^{41}$

Sobre el origen de la felicidad como medida determinante y criterio para evaluar el ideal de progreso, Tkachev escribe: "Esta medida, que a priori, por así decirlo, se deriva inductivamente de la historia de la vida humana en sociedad; ha sido adoptada desde la esencia misma, desde la meta de esta vida social". ${ }^{42}$ Permítaseme citar una extensa declaración en la que Tkachev intenta resolver, de una manera peculiar, también un problema que surge de la realidad obvia de las necesidades humanas y que podría relacionarse objetivamente con toda la gente:

La sociedad puede cumplir plenamente sus tareas solo si, en primer lugar, conecta los objetivos de vida de todos, es decir, crea condiciones de educación completamente iguales y, en el futuro, lleva todas las heterogeneidades caóticas hechas por los individuos durante los movimientos regresivos de la historia a un denominador común, a un nivel común. En segundo lugar, logra la armonía de medios y necesidades, es decir, desarrolla entre sus miembros aquellas necesidades que son posibles de satisfacer mediante la productividad del trabajo o que pueden aumentar inmedia-

${ }^{40}$ Ibid., p. 314.

${ }^{41}$ Loc. cit.

${ }^{42}$ Tkachev, "La ciencia en la poesía y la poesía en la ciencia", p. 251. 
tamente la productividad o disminuir las pérdidas, aquellas necesidades que son esenciales para el apoyo y el desarrollo del individuo. Tercero, si hay un grado posible de satisfacción igualmente garantizado para todas las necesidades de todas las personas (decimos: un grado posible porque el establecimiento de una armonía absoluta entre medios y necesidades representa un ideal apenas alcanzable). La aplicación de estas tres condiciones en la mayor medida posible representa el objetivo final de la sociedad. Es una meta completamente objetiva que surge de la esencia misma de la vida en sociedad. La vida humana en sociedad no puede tener otra tarea que la de ayudar a alcanzar los objetivos de los individuos que constituyen la sociedad. ${ }^{43}$

Esta cita da una idea clara de la comprensión del término "felicidad" dentro de la concepción del progreso. Representa una meta objetiva que, como elemento del progreso, se convierte en la meta objetiva del progreso como tal. Según Tkachev, se trata de un resultado original que ninguno de esos sectarios que idealizan subjetiva o religiosamente ha logrado jamás. Si en mi descripción de los elementos del progreso indiqué que Tkachev especifica la determinación del progreso mediante la conexión del movimiento como una actividad consciente con uno de los elementos, con una meta o continuidad de este movimiento, no por casualidad, ahora podemos ver esta intención más claramente. Como vimos, según Tkachev, nadie ha determinado hasta ahora criterios de progreso tan objetivos y obvios, nadie ha determinado la meta del progreso de una manera tan objetiva; por lo tanto, no sería posible pensar en el pensamiento progresista si el progreso consistiera necesariamente en los tres elementos objetivos. No tendría ninguna representación histórica en esta forma indivisa.

La postulación del progreso objetivo nos lleva solo a un paso de todas las grandes posibilidades que permitirá este descubrimiento basado en la obviedad.

Como clave para entrar en un mundo nuevo que hasta ahora no se ha conocido objetivamente, Tkachev utiliza intereses económicos que ya había formulado en parte.

${ }^{43}$ Tkachev, "Qué es el partido del progreso", p. 321. 
Los factores económicos son, según Tkachev, elementos dominantes en toda la historia. Escribe:

Ni las doctrinas morales ni el pensamiento crítico mueven la historia o crean su contenido genuino, que está determinado soberanamente por los afectos individuales, por las necesidades subconscientes, casi completamente instintivas. Estos afectos, estas necesidades subconscientes están determinadas por los intereses económicos del entorno en el que surgen y se desarrollan. Son como los nervios de la vida social, un alma de la historia, en la que se concentra toda la atención de un historiador. ${ }^{44}$

Sobre el efecto de las causas económicas, Tkachev escribe en otra obra:

Las causas económicas, como podemos ver, han creado y apoyado todos los enormes sinsentidos que torturaron y extirparon la razón humana durante tantos siglos. Las mismas causas económicas han eliminado y destruido todos esos sinsentidos tan pronto como la necesidad de ellos desapareció. El hecho de que toda la sabiduría de los intelectuales y todos los hermosos discursos de los apóstoles no pudieran ser puestos en práctica fue causado por el interés económico mismo. ${ }^{45}$

Tkachev demuestra el poder de las influencias económicas en varios lugares, tales como:

Cuando el dueño de una fábrica produce cierto porcentaje de ganancia, cuando un comerciante disminuye el precio de los bienes, cuando los ingleses compran esclavos en sus colonias y los barones ingleses, a su vez, compran a sus siervos, entonces creen que el estímulo no era ni filantropía ni amor a la humanidad ni motivos humanos, sino un cálculo aritmético ordinario y nada más. ${ }^{46}$

Tkachev incluso afirma que también las determinaciones religiosas están sujetas a este factor económico: "En la mayoría de los casos, todos

${ }^{44}$ Tkachev, "El papel del pensamiento en la historia", p. 173.

${ }^{45}$ Tkachev, "Ensayos de historia del racionalismo", p. 129.

${ }^{46}$ Ibid., p. 130. 
los negocios privados han tenido también algún objetivo religioso. Las expediciones de negocios han sido al mismo tiempo misiones, y las misiones, expediciones de negocios". ${ }^{47}$ A este respecto, menciona también las Cruzadas; sin embargo, también escribe que la Iglesia, con sus enseñanzas, fue a menudo un obstáculo considerable para el desarrollo de los negocios y el mercado, es decir, los hombres de negocios tenían que luchar con la autoridad de la Iglesia, lo que a menudo hacía que el poder económico prescribiera la operación de la Iglesia, y la Iglesia era un apologeta de los intereses económicos. Unas pocas páginas adelante, añade con el mismo espíritu: "La filosofía, la religión y la ciencia dominantes no representan otra cosa que un espejo en el que se reflejan y repiten con exactitud matemática las necesidades económicas de una nación en un periodo determinado". ${ }^{48}$ Va aún más lejos:

Todos los grandes cambios que se han realizado en la cosmovisión humana en una esfera moral y en una esfera de pensamiento llegaron por la influencia de determinadas relaciones económicas, de determinados intereses económicos. Como vimos, estos cambios ocurrían gradualmente y sin ser observados, no habían correspondido a los grandes descubrimientos científicos, no habían sido hechos por el poder de algún genio o un grupo de pensadores extraordinarios. Los pensadores comenzaron a difundir la incredulidad, la tolerancia o el utilitarismo mucho tiempo después de que el cálculo económico hubiera cambiado la visión de la gente sobre la infalibilidad del dogmatismo católico y sobre el papel del sufrimiento $\mathrm{y}$ el hedonismo en la vida humana. ${ }^{49}$

Así, es evidente que el poder de las influencias económicas no escapa ni siquiera a la esfera del Estado, la política y el derecho, como podemos ver, mientras que el papel del elemento económico en el campo jurídico todavía no ha sido suficientemente explicado. En este sentido, Tkachev escribe sobre el papel de las influencias económicas: "En general, se puede decir que las relaciones económicas determinan

${ }^{47}$ Ibid., p. 131.

${ }^{48}$ Ibid., p. 133.

${ }^{49}$ Ibid., p. 149. 
los elementos principales de una organización estatal. Los detalles y las particularidades están, por supuesto, determinados por el nivel de pensamiento en un país". ${ }^{50}$

La secuencia de las declaraciones de Tkachev representa uno de los resultados de sus nuevas y objetivamente válidas características del progreso que establece la felicidad de los individuos de la sociedad respectiva como la meta de la vida social. Solo la determinación de criterios objetivos nos ayuda a descubrir el número de falsedades e injusticias que ocurrieron y siguen ocurriendo, falsedades e injusticias que estaban condicionadas por influencias económicas y excusadas por cualquier cosa, y que eran percibidas como plausibles en ese momento.

Para explicar el nuevo estado, considero necesario prestar atención a un elemento esencial que tiene un papel importante en las relaciones económicas. En el contexto dado, Tkachev recalca el capital: "Todas las cualidades del ser humano, todo lo que tiene, todo lo que desea, todo por lo que se esfuerza, todo esto tiene un significado para el ser humano solo hasta el punto que puede ser capital. Tener un capital, esto es el bien más alto, esto es su objetivo final, y esto es también por lo que lucha". ${ }^{1}$ Tkachev delibera sobre el capital también en el sentido de capital mental: "Qué posición más amplia y dominante en la 34 conciencia de la mayoría tiene el término capital. Todo, ciertamente todo, incluso la honestidad, la grandeza de corazón o el amor entran en la categoría de este término". ${ }^{52}$ Se puede ver que Tkachev entiende el capital en un sentido muy amplio.

Este significado amplio del término "capital" no es por accidente. Sobre la base de su meta del progreso objetivamente determinada, Tkachev ve en el capital la cuestión clave de toda la historia:

Medios para la supervivencia: demasiado poco para el ser humano histórico, necesita tenerlos en forma de capital. Si alguna vez alcanza esta meta, dejará de pertenecerse a sí mismo, se entregará completamente a las

${ }^{50} \mathrm{Tkachev,} \mathrm{“Закон} \mathrm{общественного} \mathrm{самосохранения”} \mathrm{[“Ley} \mathrm{de} \mathrm{autoconservación} \mathrm{pública”],}$ en Сочинения В 2-x Томах. Том 1 [Obras en 2 tomos, tomo 1], Moscú, Editorial Pensamiento, p. 438.

${ }^{51}$ Ibid., p. 434

${ }^{52}$ Loc. cit. 
manos de este asunto, cuya posesión se esfuerza por lograr. El capital no le pertenece, él pertenece al capital, no administra el capital, sino que el capital lo administra a él. Lo obliga a librar constantemente una lucha que no libra para sí mismo, sino para el capital. En este momento, la lucha pierde cualquier forma de lucha por la supervivencia. Nuestro intento de encontrar un motivo mental razonable, una necesidad real o significativa de esta lucha en la naturaleza humana, terminaría sin éxito. No, el ser humano no actúa sobre la base de su propia lógica, sino sobre la lógica del capital. ${ }^{53}$

Esta idea se refiere a cierta digresión de la humanidad en relación con el capital. Lo que anhelamos y queremos lograr ha dominado a la humanidad hasta tal punto que se ha visto completamente sometida a ello. El resultado es que "la acumulación de capital y el progreso económico contribuyen sin duda alguna al desarrollo de una actividad de la razón, pero solo, por así decirlo, en una proporción cuantitativa y no también cualitativa". ${ }^{54}$ El desarrollo puede entenderse como la determinación del pensar por algo que permitió la acumulación de capital. Como uno de sus méritos — además de la meta objetiva del progreso-, Tkachev considera también la revelación mencionada, una nueva visión o más bien un impulso para la revalorización de la historia. Desde este punto de vista se puede ver que todos los ideales y valores que se habían establecido en la historia como estímulos dominantes de periodos históricos particulares, estaban determinados por las condiciones económicas plenamente dominadas por la búsqueda del capital sobre el que la humanidad perdió el control. Esta cuestión desapareció completamente de la meta objetiva (la única posible) de la historia, que es la felicidad humana. El capital que debe contener una variedad de metas y felicidad se convirtió en un desconocimiento de la meta genuina de la sociedad humana, un esclavista que gobierna la sociedad.

Las manifestaciones de perversidad derivadas de la sujeción de la filosofía y el pensamiento al capital pueden verse también — según Tkachev- en los grandes pensamientos e ideales formulados por los pensadores burgueses: "El pensador burgués resume así su comprensión

${ }^{53} \mathrm{Id}$.

${ }^{54}$ Ibid., p. 436. 
del ideal social: ¿Qué es el individuo en la sociedad contemporánea? No es nada. ¿Qué debería ser? Debería ser todo. ¿Qué es el Estado en la sociedad contemporánea? Es todo. ¿Qué debería ser? No debería ser nada". ${ }^{55}$ La idea citada de Tkachev evoca el contexto político de su obra cuando escribe sobre el enfoque de los pensadores burgueses sobre el papel del Estado: "En una palabra, el Estado se transforma de una institución política y legal en una compañía de seguros". ${ }^{56}$ Un ejemplo sin precedentes de este pensamiento burgués es — según Tkachev-el publicista y filósofo del derecho Émile de Girardin, sobre cuya filosofía escribe: "Toda la filosofía de Girardin, que se ocupa de la tarea imposible de conciliar lo irreconciliable — la libertad en una esfera legal con la libertad del capital—, está llena de contradicciones cubiertas de sofismas y alisada con capas de frases sin sentido". ${ }^{57}$ Más tarde, en relación con el pensador francés, añade: "Sí, esa es la apoteosis de la tiranía. La tiranía, la esclavitud del individuo; esa es la síntesis final de todas las contradicciones de ese principio del individualismo absoluto, que predica la filosofía burguesa". ${ }^{58}$ Señala la incapacidad de la filosofía burguesa para liberarse de la sujeción al capital, la sujeción que los filósofos burgueses no quieren admitir. Sobre la filosofía burguesa, Tkachev 36 también escribe:

Utiliza una materia prima empírica para cumplir con los marcos arbitrarios de sus sistemas metafísicos. Puesto que los sistemas no son capaces y no pueden llevar nada a la concordancia mutua, no puede haber ninguna armonía, ninguna unidad. No pueden descubrir ni clarificar esas leyes científicas incondicionales, sin el conocimiento de cuya filosofía social se perderán para siempre en la oscuridad, y se perderán en sus propias contradicciones, mientras se inclinan ante la praxis con la lisonja de un esclavo que produce un eco, en lugar de analizarlas y gobernarlas valientemente.

${ }^{55}$ Tkachev, "Утопическое государство буржуазии" ["Estado utópico de la burguesía”], en Сочинения В 2-х Томах. Том 1 [Obras en 2 tomos. Tomo 1], Moscú, Editorial Pensamiento, p. 349.

\footnotetext{
${ }^{56}$ Loc. cit.

${ }^{57}$ Ibid., p. 351.

${ }^{58}$ Ibid., p. 364.
} 
Se enorgullece de que sigue estrictamente los hechos y no admite ninguna fantasía; lo llama realismo sobrio. ${ }^{59}$

Así pues, las obras de Tkachev pueden caracterizarse de la siguiente manera: El punto central de su interés es el esfuerzo por determinar el criterio objetivamente válido del progreso como el ideal que regula la acción humana, o más precisamente, la acción revolucionaria elaborada sistemáticamente. Con su organización, recuerda la estructura del ejército con sus oficiales y las filas, o para ser más precisos —en opinión de Tkachev_- el partido fuerte con una unidad de control ejecutivo como un comité y los miembros ordinarios del partido, los ejecutores de la revolución. Para Tkachev, este ideal con su función estimulante está ligado principalmente a un grupo de revolucionarios, es decir, a aquellos que llevan a la práctica la revolución. En el proceso de determinación del ideal objetivamente válido dentro de la concepción de Tkachev, el historiador y la historia tienen un estatus importante en cuanto ciencia que trabaja con el pasado, que se percibe como un espacio lleno de sucesos, fenómenos sociales y cambios. La historia representa el suelo que es capaz de absorber y utilizar de manera más eficaz las influencias de verdades objetiva y absolutamente válidas. Al mismo tiempo, es capaz de revalorizar su propio impacto y también los errores que se han cometido en otros campos de la acción humana activa. Y finalmente, la historia puede proporcionar a los revolucionarios todo lo que necesitan para la realización de la revolución y para la transformación del país durante "el segundo día después de la revolución".

Podemos imaginar que la confrontación de las opiniones de Tkachev con sus contemporáneos, así como con los últimos historiadores del pensamiento filosófico, dio lugar a opiniones decididamente críticas hacia sus obras. Muchos de ellos recomendarían colocar las obras del populista ruso en fondos de archivo titulados Nunca más vuelva a leerse un disparate tan descarado. A pesar de los sentimientos encontrados causados por este título imaginario, considero que una investigación ulterior del pensamiento de este autor ruso sigue siendo valiosa. Creo

${ }^{59}$ Ibid., p. 371. 
que sus observaciones, que apuntan a cambios sociales de costoso pago, o sus reflexiones sobre las influencias que determinan la visión de un historiador sobre la historia, son extraordinariamente estimulantes. Sin embargo, no me puedo librar de la convicción de que el espíritu creativo de este autor ruso se ve considerablemente menospreciado por la forma en que se perfila revolucionariamente en el discurso intelectual de la época, y por la forma violenta y, permítaseme decir, artificial en que estipula sus postulados. En mi lectura de Tkachev no he encontrado ningún momento que refute mi convicción de que él mismo sirve como confirmación de la necesidad de lo que tanto critica, es decir, de actitudes subjetivas. Para mí, representa un ejemplo negativo de lo esencial que es la presentación de los pensamientos de un filósofo, así como la forma de su participación en el discurso social en relación con cierto campo temático. Sin embargo, el hecho es que sus opiniones no eran marginales, sino que, por el contrario, resonaban en ese momento. El estudio de las obras de Tkachev tiene, además del contexto estrictamente populista, un significado mucho más amplio: sus ideas representan una base valiosa para nuestra comprensión en contextos más amplios de la historia del pensamiento filosófico, político y social de la provincia rusa. Estos contextos presentan un continuo histórico y han marcado permanentemente una característica no solo de Rusia, sino también del mundo entero. Me refiero aquí a las interacciones mutuas de la tradición populista y al legado de las obras de Tkachev dentro de las obras de Lenin en particular.

Como dije, este tema es extraordinariamente delicado en el entorno del antiguo bloque del Este. Se trata, sin duda, de un tema que requiere nuevas lecturas que puedan enriquecer cuestiones aún abiertas, como señala uno de los historiadores más importantes, Leszek Kołakowski:

El carácter del leninismo ${ }^{60}$ como variante de la doctrina marxista ha sido objeto de una dilatada controversia. La cuestión es si, en particular, el leninismo es una ideología "revisionista" en relación con la tradición

${ }^{60}$ En relación con el término "leninismo", cabe destacar que ni en el trabajo de Walicki ni en el trabajo de Kołakowski se puede encontrar ninguna diferencia en el uso del término "leninismo" y el legado, obras u opiniones del propio Lenin. 
marxista o, por el contrario, una fiel aplicación de los principios generales del marxismo a una nueva situación política. ${ }^{61}$

De esta manera, Kołakowski señala la naturaleza problemática del legado de Lenin. Permítaseme señalar que esta cuestión puede ser aún más distintiva cuando se trata de las conexiones de las obras de Lenin con el populismo ruso y con Tkachev en particular. El alcance de la cuestión como tal es un asunto peculiar. Sin embargo, estoy convencido de que las nuevas lecturas requieren definitivamente una discusión sustancial de expertos sobre la naturaleza de estas nuevas lecturas, así como sobre la naturaleza de un estudio sistemático del tema, y no me refiero solo a "desempolvar" las obras selectas de Lenin.

En esta fase de mi investigación, no tengo ninguna ambición de esbozar la naturaleza de la nueva lectura ni de ofrecer una especificación clara y estricta de la influencia de Tkachev sobre Lenin. Mi intención es dar una idea de la posible naturaleza de esta relación, para señalar algunas características problemáticas y las tareas que enfrentará todo aquel que desee participar en esta investigación.

Como dije, procederé de las obras de dos historiadores polacos: Walicki y Kołakowski. El primero marca el año 1903 como punto de inflexión: fue el año en que el Partido Socialdemócrata Laboral ruso se dividió en dos facciones: bolcheviques y mencheviques. Según Walicki, hasta ese año tuvo lugar la lucha intensa y estrictamente ideológica entre marxistas y populistas.

Partiendo de estas fuentes, describiré los marcos generales que pueden ser percibidos como las condiciones y circunstancias de las posibles confrontaciones de Lenin con el legado populista. Finalmente, esbozaré varias formas de interacción entre la tradición populista como tal y el leninismo, y también entre Tkachev y Lenin.

El ambiente en el que el joven Lenin creció y se formó intelectualmente, con la influencia de su hermano mayor Alexander, está lleno de ideas sobre el populismo radical. Es posible decir que Lenin se relaciona principalmente con las opiniones producidas por la rama radical y

${ }^{61}$ Kołakowski, Las principales corrientes del marxismo, II, p. 375. 
terrorista del movimiento populista que — según Walicki-, vinculó el marxismo (en el campo de la economía) con el radicalismo político de Tkachev. En este contexto, añadiría que las ideas populistas no pueden ser percibidas como una identificación inmediata y general con las actitudes económico-filosóficas del marxismo clásico. En gran medida, se parte de un pueblo agrario que no puede ser plenamente identificado con el proletariado de Marx..$^{62}$ En esta atmósfera se encuentra también el origen de una actitud común de una parte de los populistas radicales como Tkachev y Lenin, la convicción de que

los países subdesarrollados son los más cercanos al socialismo; el desarrollo de la civilización en las condiciones capitalistas no aumenta, sino que disminuye las posibilidades de la revolución socialista. La única oportunidad del socialismo es una interrupción del desarrollo capitalista en el momento oportuno. El socialismo tiene más posibilidades en España e Italia que en Inglaterra, Francia y la Alemania de Bismarck [...]. El socialismo tiene las mayores oportunidades en Rusia. ${ }^{63}$

Como podemos ver, es posible comparar las posiciones de estos temas. Walicki lo señala también en otra parte de su obra, cuando define tres tipos de inteligencia revolucionaria rusa.

El primer tipo se llama "racional", y tiene una relación religiosoemocional con su doctrina. Walicki denota el segundo tipo con el

${ }^{62}$ La cuestión principal es que el modo de vida agrario de la servidumbre rusa implicaba un orden social específico y una organización social llamada obshchina [“comuna, comunidad rural"]. Broda se refiere a las actitudes de los populistas rusos hacia la obshchina de la siguiente manera: "La comunidad rural rusa (obshchina) y sus formas de vida social autónoma, mir ['sociedad'], recibió una atención extraordinaria de parte de los representantes de la intelligentsia, pues veían ahí los fundamentos del futuro sistema social y económico de Rusia"; Ambivalencias nacionales. Entre la apoteosis del pueblo y el teorema, p. 87. A este respecto, Isaiah Berlin señala lo siguiente: "Todos los populistas estaban de acuerdo en que la comuna del pueblo era el embrión ideal de aquellos grupos socialistas en los que se iba a basar la futura sociedad"; Russian thinkers, 1994 Londres, Penguin Books, p. 219. Pipes escribe: "Mir — la comuna del pueblo- significaba también 'el mundo'. La comunidad refrenó los impulsos antisociales del mujik [“campesino, agricultor"]: el colectivo era superior a sus miembros individuales"; Rusko za starého režimu ["Rusia bajo el antiguo régimen"], 1997, Praga, Argo, p. 158. Y Bazylow añade: "Sin el permiso de todo el mir, un campesino no podía deshacerse de la parcela racionada ni abandonar la aldea"; Historia Rosji ["Historia de Rusia"], 1985, Breslavia, Ossolineum, p. 325.

${ }^{63}$ Walicki, La idea de la libertad para los pensadores rusos, pp. 239-240. 
atributo de "dogmático-racional", porque acepta acríticamente el culto a la ciencia. El tercer tipo de inteligencia es la pragmática, que desprecia todos los dogmas y principios, pretende alcanzar su objetivo a cualquier precio y "está representada por Necayev, Tkachev y, en gran medida, por Lenin". ${ }^{64}$ El enfoque de Walicki permite no solo hacer una comparación de estos temas, sino también identificar sus actitudes comunes.

Una de sus similitudes se observa en el aspecto terminológico. Walicki señala que el término "clase obrera" utilizado por Lenin es definitivamente término populista y fue objeto de burla entre los círculos marxistas. En relación con el campo terminológico, también señala la semejanza entre Lenin y los populistas en su uso del término "democrático" en sus primeras obras: ${ }^{65}$ "La palabra 'democrático' es para Lenin (al igual que para los populistas) lo contrario de la palabra 'burgués, liberal"". ${ }^{6}$

Sin embargo, estas similitudes no son inherentes a toda la escala de cuestiones relativas a la relación entre Lenin y los populistas. Kołakowski resume la continuidad ideológica de Lenin y su interés en la tradición populista junto con su intención de revalorizarla críticamente de la siguiente manera: "El mérito de los populistas, según Lenin, estuvo en que fueron los primeros en plantear la cuestión de las contradicciones económicas del capitalismo en Rusia, aunque no tenían otra respuesta que ofrecer que la idea reaccionaria de una edad de oro". ${ }^{67}$ Podemos ver que Lenin está al margen del populismo radical estrechamente vinculado solo con Tkachev. Tkachev puede ser visto como un elemento de enlace, una conexión funcional en la relación entre Lenin y los populistas radicales. También está a favor de esta postura Walicki, quien, en relación con la enseñanza del populista Bakunin, escribe: "El vínculo más importante entre Bakunin y Lenin es sin duda Tkachev. Bakunin imaginó que después del triunfo de la revolución, la organización centralizada y autoritaria pronto sería innecesaria. Tkachev no vivía en esa

${ }^{64}$ Ibid., p. 249.

${ }^{65}$ Walicki menciona tres periodos significativos de las obras y actividades de Lenin: 1) hasta 1903; 2) los años revolucionarios 1905-1906; y 3) después de 1917. Por lo tanto, las obras tempranas caen dentro del primer periodo.

${ }^{66}$ Ibid., p. 260.

${ }^{67}$ Kołakowski, Las principales corrientes del marxismo, II, p. 313. 
ilusión. Según su opinión, después de la victoria de la revolución sería inevitable una dictadura revolucionaria que controlara la vida social en general (incluida la vida espiritual). El poder pertenecería a los trabajadores supervisados por el partido (inteligencia), aunque fueran una minoría". ${ }^{68}$ Aquí podemos ver un elemento que puede ser considerado como el cambio a una dimensión crucial de este artículo, es decir, la posibilidad de percibir a Tkachev como un predecesor ideológico inmediato de Lenin. Junto a la capacidad de resistir el "engaño" de la insignificancia del partido tras la victoria de la revolución, surge también el motivo de la minoría, que puede ser considerado como el motivo clave en un eje de interacción entre Tkachev y Lenin. Quiero subrayar que la minoría mencionada no es otra cosa que el partido revolucionario. En este sentido, Lenin no oculta su admiración por Tkachev, la que probablemente se deriva del hecho de que no pudo encontrar ningún apoyo sustancial para este asunto en las obras de Marx. Kołakowski señala el hecho de que aunque Marx no equiparó al proletariado en su conjunto con el partido, "nunca dijo exactamente qué era el partido". 69 Marx estaba convencido del incontenible poder del proletariado, que Lenin negó resueltamente. Tanto Lenin como Tkachev se negaron decididamente a basar una campaña revolucionaria exitosa en los esfuerzos desenfrenados del movimiento obrero, por muy resuelta que fuera. Estoy de acuerdo con la opinión de Kołakowski de que "la cuestión central de la perspectiva del socialismo era, afirmaba [Lenin], la conciencia teórica del movimiento revolucionario, y esta no podía desarrollarse en modo alguno a partir del movimiento espontáneo de los trabajadores" ${ }^{70}$ La misma actitud se puede encontrar también en Walicki:

Un papel importante que Lenin asignó a un partido bien organizado, ordenado jerárquicamente, y controlado centralmente, había procedido de una profunda desconfianza en el poder y las habilidades del movimiento obrero desenfrenado. Los trabajadores dependientes de sí mismos pueden, en el mejor de los casos, llegar a un sindicalismo, es decir, a una sujeción

\footnotetext{
${ }^{68}$ Walicki, La idea de la libertad para los pensadores rusos, p. 267.

${ }^{69}$ Kołakowski, Las principales corrientes del marxismo, II, p. 383.

${ }^{70}$ Ibid., p. 380.
} 
ideológica a la burguesía. El partido (o mejor dicho, la dirección del partido) en la concepción de Lenin debería cumplir el mismo papel que la inteligencia en las concepciones de los populistas, principalmente en la de Nechayev y Tkachev. ${ }^{71}$

Si Walicki señala el papel clave de la inteligencia dentro de las concepciones populista de Nechayev y Tkachev, hay que recordar que Tkachev también trabaja con el motivo del partido. Para avanzar a partir de esta declaración, permítaseme referirme brevemente a la reacción inmediata de Lenin a la mencionada dimensión teórico-organizativa del legado de Tkachev. Eso también nos permitirá identificar la característica más crucial de la relación de Lenin con el legado de Tkachev.

Procederé a partir del análisis de Walicki del conocido trabajo de Lenin ¿Qué hay que hacer $?^{72}$ Walicki comenta que Lenin pretendía formar una organización centralizada y secreta de revolucionarios profesionales, y señala que "Lenin llamó grandioso el plan tkacheviano de obtener el poder". ${ }^{73}$ Se puede encontrar una evaluación más precisa en Kołakowski:

Los historiadores han acentuado a menudo su papel [de Tkachev] como precursor de Lenin en este punto. La asociación populista clandestina fundada en 1876 y conocida como Zemlya i volya (Tierra y Libertad), debía sus ideas organizativas a Tkachov [sic], aun cuando este no asumió su ideología social. Lenin, aun habiendo mostrado un gran desprecio por los populistas, sobre todo en su última fase, tuvo un gran respeto por las tradiciones organizatorias del movimiento populista clandestino. ${ }^{74}$

Además de las declaraciones inmediatas de los historiadores, la conexión en la línea Tkachev-Lenin se puede notar también en una crítica dirigida a Lenin: "Los mencheviques, al igual que Rosa Luxemburgo, acusaron regularmente a Lenin de blanquismo, por proponerse destruir

${ }^{71}$ Walicki, La idea de la libertad para los pensadores rusos, p. 262.

${ }^{72}$ En 1863, 39 años antes que Lenin, Chernishevski (uno de los fundadores del movimiento populista) escribió una obra con el mismo título. Se dice que Lenin se sabía de memoria esta obra.

${ }^{73}$ Walicki, La idea de la libertad para los pensadores rusos, p. 261.

${ }^{74}$ Kołakowski, Las principales corrientes del marxismo, II, p. 321. 
el orden existente por medio de un coup d'état que abarcaba la ideología conspiratoria de Tkachov [sic]". ${ }^{75}$ Una organización de actividades revolucionarias, una clasificación estricta, disciplina y marcos claramente definidos; estos fueron los aspectos del concepto de Tkachev del partido revolucionario que más atrajeron la atención de Lenin. Me gustaría subrayar que baso esa opinión en las fuentes secundarias, es decir, en los textos de los historiadores con los que he trabajado. He elegido esa actitud intencionadamente y soy consciente de todas las dificultades admisibles. Debe tomarse como mi expresión de respeto tanto al tema como al lector. La segunda parte de este artículo pretendía "únicamente" mostrar que el vínculo entre Tkachev y Lenin existe y que hay buenas razones para examinar la línea populistas-TkachevLenin y viceversa. Este contexto abre un gran espacio para la investigación, a pesar de las dificultades ocultas.

En el curso de la interpretación de la proximidad ideológica del populismo al leninismo, nos topamos con la cuestión de la ambigüedad terminológica, de cierta vaguedad por parte de Lenin en el uso de los términos. Por eso Walicki envía un mensaje a los futuros historiadores, diciendo que "la esencia del leninismo tiene que ser descubierta en su escondite". ${ }^{76}$ Refleja la naturaleza de la cuestión terminológica de la siguiente manera:

La complicación básica en cuanto a la escritura sobre el leninismo es la necesidad de "leer entre líneas". Lenin no sometió su práctica a la "ortodoxia"; sin embargo, renunció involuntariamente a las formulaciones tradicionales "ortodoxas" dentro del campo de la teoría: en lugar de rechazarlas, prefirió usarlas y les atribuyó - a menudo por medio de extraños métodos interpretativos - un contenido completamente diferente. Intentó camuflar (también ante sí mismo) su revisionismo a cualquier precio. ${ }^{77}$

Todos aquellos que estén interesados en el estudio del legado de Lenin deberían tenerlo en cuenta.

${ }^{75}$ Ibid., p. 389.

${ }^{76}$ Walicki, La idea de la libertad para los pensadores rusos, p. 258.

${ }^{77}$ Loc. cit. 
Walicki señala que no es posible percibir el legado de Lenin como un capítulo en la historia del marxismo, y en absoluto como parte de la historia del proletariado internacional. "El leninismo es algo menos y algo más al mismo tiempo. El problema del leninismo es un problema de toda Rusia y de toda su historia, junto con su carácter europeo y asiático, su movimiento revolucionario y sus cuatrocientos años de autocracia zarista". ${ }^{78}$ Por otro lado, Walicki hace hincapié en la necesidad de llevar a cabo una investigación interdisciplinaria y de tener en cuenta una amplia gama de variables: "La investigación debe hacerse mediante la selección constante de la importancia de las diversas declaraciones de Lenin, revelando diversos significados en formulaciones que parecen ser idénticas a primera vista, mediante la confrontación permanente de los pensamientos leninianos con el marxismo clásico, con diferentes tipos de marxismo ruso y con el pensamiento revolucionario ruso tradicional". ${ }^{79}$ Walicki esboza muchos problemas y dificultades ocultos de este examen. En cierto sentido, puede ser visto como un estímulo para los historiadores, aunque la investigación nunca se concluya. Como dice el credo de la hermenéutica, la historia debe reescribirse constantemente.

En mi opinión, la cuestión asociada, el problema que se plantea ante posibles investigaciones futuras, es también la cuestión con la que voy a concluir esta investigación: ¿Podemos decir con certeza cuáles son las ideas genuinas de Lenin? ¿No deberíamos empezar con la selección entre el auténtico legado de Lenin y el leninismo de las "obras selectas"?

${ }^{78}$ Ibid., p. 269.

${ }^{79}$ Ibid., pp. 258-259. 
Se prohíbe su reproducción total o parcial por cualquier medio, incluido electrónico, sin permiso previo y por escrito de los editores. 